\title{
Modulation of Aromatase (CYP19) Gene in the Testis of Mice Under the Exposure of 4-Nonylphenol
}

\section{Kusum Kusum ${ }^{1}$, Ashish Ashish ${ }^{2}$, Sangeeta Rai ${ }^{3}$, Royana Singh ${ }^{2}$ and Radha Chaube ${ }^{1 *}$}

${ }^{1}$ Department of Zoology, Institute of Science, Banaras Hindu University, Varanasi, India

${ }^{2}$ Department of Anatomy, Institute of Medical Science, Banaras Hindu University, Varanasi, India

${ }^{3}$ Department of Obstetrics and Gynaecology, Institute of Medical Science, Banaras

Hindu University, Varanasi, India

*Corresponding Author: Radha Chaube, Department of Zoology, Institute of Science, Banaras Hindu University, Varanasi, India.
Received: May 31, 2021

Published: June 29, 2021

(C) All rights are reserved by Radha Chaube., et al.

\begin{abstract} profiling. BALB/C male mice testis having its exposure for about 21 days followed by gene expression studies. 21 days. samples.

Conclusion: 4-NP has an estrogenic effect on testes of male mice.

Keywords: 4-Nonylphenol (4-NP); Testis; Endocrine Disrupting Chemicals (EDCs); Gene Expression
\end{abstract}

Background: 4-Nonylphenol (4-NP) is an Endocrine Disrupting Chemical (EDC), which interferes with endocrine (hormonal) system at certain doses. It is the primary final degradation product of Alkylphenolethoxylates (APE) which is a non-ionic surfactant, widely used in industries, agriculture and domestic purposes. 4-NP is a persistent and ubiquitous Xenoestrogen with endocrine disrupting activities. It is highly prevalent in aquatic environments and is moderately bio-accumulative due to its lipophilic nature. Several studies have reported adverse effects of 4-NP on male reproductive system, including testicular abnormalities with gene expression

Objective: The aim of our study was to investigate the multidimensional effects of 4-NP at varying doses (control, low and high) on

Materials and Methods: Male mice were given oral doses $21.25 \mathrm{mg} / \mathrm{kg}$ BW (Low Dose) and $85.0 \mathrm{mg} / \mathrm{kg}$ BW (High dose) of NP for

Result: The aromatase gene expression in low and high dose tissue samples varies (slightly higher) in respect to control testis

\section{Introduction}

Over the past few years, a large number of studies trend a growing concern with respect to exposure of chemicals that can interact with the endocrine system and causes adverse effects on wildlife and humans as well. The group of pollutants that majorly affect the endocrine system in organisms are Endocrine disrupting chemicals (EDC's). Thus, from a physiological perspective, an endocrinedisrupting substance is a compound, either natural or synthetic, which, through environmental or inappropriate developmental exposures, alter the hormonal and homeostatic systems that enable 
the organism to communicate with and respond to its environment [1]. Among the myriad of chemicals present in air, water, food and in a variety of consumer products, many are capable of interfering with the endocrine system of animals and humans [2].

Alkylphenolpolyethoxylates (APEs) are non-ionic and costeffective surfactants, widely used for domestic and commercial purposes. From textile, petroleum, pulp and paper production in the industrial sector, pesticide formulations in agricultural sector to even household cleaning agents, cosmetic products and plasticwares etc, these APEs have been a part of our daily life from the very beginning. Most of these APEs are discharged to sewer system, and further reach to wastewater treatment plants, where these get biodegraded to Alkylphenols (APs) under the action of mainly anaerobic microorganisms. Most of the APs bind to estrogen receptors in a concentration dependent manner, potentially acting as an activator (agonist) or inhibitor (antagonist) of cellular responses [3]. The most relevant AP is Nonylphenol (NP) and it's one such isomeric form is 4-NP. NP is persistent and ubiquitous [4], and is detected in surface and ground water, sediments, aquatic organisms, waste water effluents, air and food products [5]. NP have effects on Testosterone biosynthesis [6] and can inhibit hCG induced testosterone release in rat Leydig cells [7]. Estrogens are produced by the aromatization of androgens, including those produced by the adrenal gland, by a complex series of reactions catalysed by a single microsomal Aromatase, P450aro' [8]. So, the expression of aromatase gene will reveal the effect of NP in male mice, to whether the androgen (primary male hormone) expression varying and leading to feminism or not. Female mice have menstrual cycle with oestrus cycle, and both of these are regulated by hormones. So here female mice were not taken into consideration for the experiment as if there be any imbalance in hormone homeostasis due to menstrual cycle, it may be under taken due to exposure of 4-NP. The main tissue selected here was testes, being a primary site for steroidogenesis and an endocrine organ as well. The genes selected for expression studies include Cyp19 (P450arom) from P450 family and a housekeeping genes GAPDH. By tracing the interference of 4-NP our aim was to study about how expression of this steroidogenic gene get modulated in male mice after an exposure to EDC's (4-NP).

\section{Material and Methods}

Study design

This study was performed at the Department of Zoology, Institute of Science, in collaboration with Department of Anatomy, Insti- tute of Medical Science, Banaras Hindu University, Varanasi, Uttar Pradesh, India, between the period January-August 2020. Ethical clearance was obtained from the Institutional Ethical Committee (Reference No: Dean/2020/MCE/2033 Dated15.07.2020).

\section{Chemicals and reagents}

4-Nonyl Phenol (CAS register no: 84852-15-3, 99\% purity, Molecular formula- $\mathrm{C}_{15} \mathrm{H}_{24} \mathrm{O}$, MW-220.35 g/mol, Density-0.9400 g/ $\mathrm{ml}$ ) mixture of isomers was purchased from ACROS Organics. It is soluble in water at $25^{\circ} \mathrm{C}$ and the solubility reported is $7 \mathrm{mg} / \mathrm{L}$ or $0.007 \mathrm{mg} / \mathrm{ml}$.

\section{Animal collection and acclimatization}

Adult male mice (25 - 30g and 70 - 80 days old) of BALB/c strain were used for this experiment. Mice were maintained under hygienic conditions in a well-ventilated room at $25-28^{\circ} \mathrm{C}$ with 12 hours photoperiodic (8am-8pm). These were provided pellet food and drinking water. The maintenance of animals was done in accordance with the guidelines of the Committee for the Purpose of Control and Supervision on Experiments on Animals, Government of India (CPCSEA, 2003).

\section{Experimental design}

A total of 30 adult male mice were selected to conduct the experiment and they were divided into three groups (Control, Low dose and high dose). Each of this group contained 10 male mice and they were kept for 7days acclimatization. NP was dissolved in water and was administered by oral gavage to all treatment groups for 21 days. The $\mathrm{LD}_{50}$ of 4-Nonyl Phenol is $170 \mathrm{mg} / \mathrm{kg}$ Body Weight [9]. The doses were designed on the basis of $\mathrm{LD}_{50}$ of NP and were continued for 21 days. $\mathrm{LD}_{50}$ is an abbreviation for lethal dose, $50 \%$ or median lethal dose. It is the amount of a substance (usually per body weight) that causes mortality of $50 \%$ of the test animal population:

- Control group (n = 10): Mice were freely allowed to feed standard laboratory pellets and water.

- Low dose group $(\mathbf{n}=\mathbf{1 0})$ : One eighth of $\mathrm{LD}_{50}$ of NP was selected for low dose i.e. $21.25 \mathrm{mg} / \mathrm{kg}$ BW. Mice were given NP dose along with normal pellet and water.

- High dose ( $\mathbf{n}=\mathbf{1 0})$ : Half of $\mathrm{LD}_{50}$ of 4-NP was selected as high dose i.e. $85 \mathrm{mg} / \mathrm{kg}$ BW. Mice were given NP dose along with normal pellet and water. 


\section{Tissue collection}

After 21days of dose administration mice were first anesthetized and sacrificed by decapitation. Then the testes tissue samples were collected and were kept at $-20^{\circ} \mathrm{C}$ for further uses.

\section{RNA isolation and cDNA synthesis}

Testes were dissected out from both control and treated groups of mice and about $100 \mathrm{mg}$ tissue was taken in centrifuge tubes. The respective tissues were marked on the tubes and were stored in icebox. Later, $1 \mathrm{ml}$ QaIAzol reagent was added in each tube. The tissues were then homogenized and $200 \mu \mathrm{l}$ of chloroform was added to it. The tubes were spin in the vortex for few seconds to allow proper mixing. The tubes were then centrifuged at $12000 \mathrm{rpm}$ for $15 \mathrm{~min}, 4^{\circ} \mathrm{C}$ and supernatant was collected in separate labelled Eppendorf tubes. $600 \mu \mathrm{l}$ of isopropanol was added and vortexed for $10 \mathrm{~min}$. The tubes were again centrifuged at $12000 \mathrm{rpm}$ for $10 \mathrm{~min}$, $4{ }^{\circ} \mathrm{C}$. The supernatant was decanted and RNA pellet was seen viable at the bottom. The tubes were spin again on vortex for detachment of pellets. $1 \mathrm{ml}$ of $75 \%$ alcohol was added to pellet for washing and then centrifuged at $12000 \mathrm{rpm}$ for $5 \mathrm{~min}, 4^{\circ} \mathrm{C}$. This washing step was repeated 3 times and finally tubes were dried in Laminar Chamber for 1 hour to allow proper evaporation of ethanol. $30 \mu \mathrm{l}$ Nuclease free water was added to dissolve pellets and further tubes were kept in freeze $\left(4^{\circ} \mathrm{C}\right)$ for 1 hour. RNA quantification was carried out by Nanodrop and further calculations were done.

\section{cDNA Synthesis by reverse transcriptase PCR}

For cDNA synthesis PCR was run. RNA quantities were noted and accordingly amount of water was added to it, to makeup the volume $11 \mu \mathrm{l} .4 \mu \mathrm{l}$ buffer, $1 \mu \mathrm{l}$ each of RNAse inhibitor, Reverse Transcriptase, Random primer, $2 \mu \mathrm{l}$ dNTPs were added sequentially. The reaction mixture corresponded to $20 \mu \mathrm{l}$ in total and the PCR tubes were finally kept in the PCR machine. The thermal conditions were $25^{\circ} \mathrm{C}$ for $5 \mathrm{~min}, 42^{\circ} \mathrm{C}$ for $1 \mathrm{~min}, 70^{\circ} \mathrm{C}$ for $5 \mathrm{~min}$, and lastly $4^{\circ} \mathrm{C}$ up to end of the process. The total running time was about 1 hour and
$20 \mathrm{~min}$.

\section{Primer designing}

From NCBI website, nucleotide option was selected and the gene name GAPDH was typed individually along with model organism name Mus musculus (Mice) and one variant was chosen from the results. FASTA sequence was obtained, copied and pasted on a world file. PICK PRIMERS option was then selected and sequence was pasted/uploaded there with a '>' sign preceding the sequence. The required entries were made, checked and finally GET PRIMERS was selected. One variant was chosen as per our working criteria. Similar steps were followed for the aromatase (CYP19) gene.

\section{qPCR (Quantitative polymerase chain reaction)}

About $100 \mathrm{mg}$ of testes tissue were used for the extraction of total RNA using the RNeasy mini kit (Qiagen). RNA purity was checked by calculating A260/A280 ratio and samples giving a ratio above 2.0 were used. The samples were treated with DNAse I before proceeding for the first strand cDNA synthesis. Five micrograms of total RNA were reverse transcribed using random hexamer primers and Revert Aid M-MuLV reverse transcriptase in a 20$\mu \mathrm{L}$ reaction volume (first strand cDNA synthesis kit, Fermentas), using the manufacturer's protocol. Quantitative PCR assays were performed for different samples using specific primers (Table 1) and VeriQuest TM SYBR Green qPCR master mix with ROX (Affymetrix, Inc. Cleveland, OH, USA) in an ABI Prism 7500 thermal cycler (Applied Biosystems, Foster, CA, USA) at $95^{\circ} \mathrm{C}(15 \mathrm{~s}), 60^{\circ} \mathrm{C}(1 \mathrm{~min})$ for 40 cycles. Each PCR sample was run in triplicates and with a final volume of $20 \mu \mathrm{L}$. This $20 \mu \mathrm{L}$ sample contains $1 \mu \mathrm{L}$ of cDNA, 10 $\mathrm{pM}$ of each primer, and $10 \mu \mathrm{L}$ of SYBR Green PCR master mix. Cycle threshold (Ct) values were obtained from the exponential phase of PCR amplification and target gene (CYP19) expressions were normalized against the gapdh gene expression to generate $2-\Delta \Delta \mathrm{Ct}$ values to quantify the target gene abundance.

\begin{tabular}{|l|c|c|c|c|}
\hline S. No. & \multicolumn{2}{|c|}{ Adaptations (Primer pairs) } & Sequences (5'-3') & $\begin{array}{c}\text { Amplicon } \\
\text { Size (bp) }\end{array}$ \\
\hline 1 & CYP19(Aromatase) & $\mathrm{F}$ & ATCCACTGGCGGGTTTTCTCTAT & \\
\hline & & $\mathrm{R}$ & CTTGGTCCCGATTCCCATCTACG & 278 \\
\hline 2 & GAPDH & $\mathrm{F}$ & AGTCCGCTCTGCTCCTCAATCG & \\
\hline & & $\mathrm{R}$ & TCGCGACCAAACGTTGCGTACC & 157 \\
\hline
\end{tabular}

Table 1: Details of the specific primers for GAPDH and Aromatase gene of BALB/c mice, where F: Forward Primer, R: Reverse Primer. 


\section{Results}

The expression of aromatase gene (CYP19) was determined in fresh testis tissue samples of balb/c mice, in 4-np treated groups and control. The expression of aromatase gene was least abundant in low dose (21.25 mg/Kg BW) 4-NP treated mice testes with increasing expression in high dose $(85.0 \mathrm{mg} / \mathrm{Kg} \mathrm{BW})$ group. It is well known that steroidogenesis in Leydig cells is characterized by sequential actions converting cholesterol into different steroid classes and androstenedione get converted into estrone or oestradiol during which CYP19, 3 $\beta$-HSD, CYP11A1 and StAR are responsible for the rate limiting steps [10]. Our previous study has demonstrated that different doses of 4-NP affect and causes decreases of testosterone production in male mice after 21 days exposure [11]. And this experiment is demonstrating higher aromatase gene expression, leading to higher estrogenic levels leading to feminism, as es-

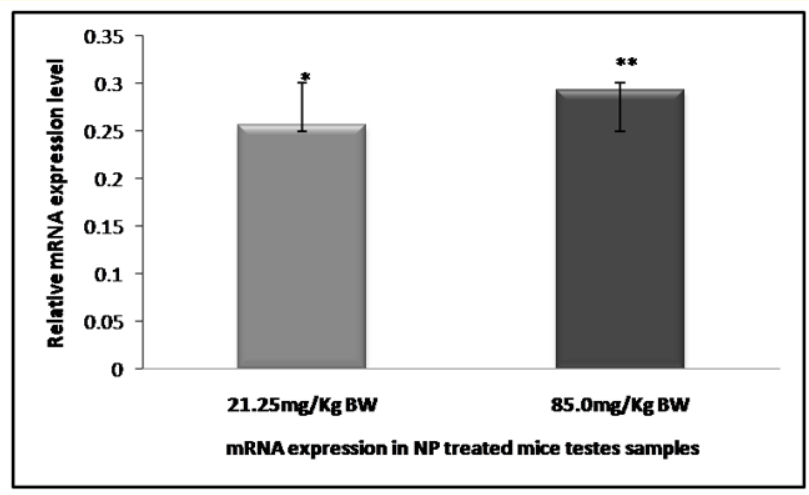

Figure 1: Expression of aromatase mRNA (mean $\pm \mathrm{SEM}$ ) in low $(21.25 \mathrm{mg} / \mathrm{Kg} \mathrm{BW})$ and high dose $(85.0 \mathrm{mg} / \mathrm{Kg} \mathrm{BW})$ testes samples of mice treated with NP. The expression levels are relative values compared to the expression in control testes samples and normalized with level of GAPDH mRNA expression.

trogen is a female reproductive hormone.

\section{Discussion and Conclusion}

In the present study, 4-NP was administered to mice by oral gavage, as humans are primarily exposed to hazardous compounds mostly through their diet. Laboratory studies on animals have demonstrated an adverse effect of NP, such as on reproduction, development, neurotoxicity and inflammation [12,13]. Over the last two decades, work using transgenic mouse models revealed that oestrogens are critical for normal development and function of male reproductive and nonreproductive organs. A recent study has shown that in male mice, 4-NP had an adverse effect on organ weight, spermatogenesis, sperm quality and causes hormonal imbalance, leading to increased toxicity and anomalies in its organs [11]. This experiment traces the effect of NP on reproductive organ of male mice, which are given a particular dose for 21 days. The results are showing, the estrogenic effects in male mice and provides an overview for understanding its physiological roles on their reproductivity. Thus, one can conclude the toxicological effects are exerted by NP in reproductive and physiologically important organs probably by affecting the endocrine system or changes in other hormonal functions. As NP is an endocrine disruptor having an adverse effect on the health of the organisms by damaging reproductive systems in species and these damages are complicated occurring via complicated mechanisms. The enzymatic disturbances in steroidogenic pathway might be one of these mechanisms and by considering the role of these in reproduction, one can conclude that these toxins exert their adverse effects on the reproduction

\section{Bibliography}

1. Papalou 0., et al. "Endocrine disrupting chemicals: An occult mediator of metabolic disease". Frontiers in Endocrinology 10 (2019): 112.

2. Auger J., et al. "Integrative rodent models for assessing male reproductive toxicity of environmental endocrine active substances". Asian Journal of Andrology 16.1 (2014): 60-70.

3. Lukacova J., et al. "The toxic effect of 4- nonylphenol on male reproductive system". Journal of Microbiology, Biotechnology and Food Sciences 2.1 (2013): 1455-1468.

4. Gautam GJ., et al. "Toxicity and tissue accumulation of 4 -nonylphenol in the catfish Heteropneustesfossilis with a note on prevalence of 4-NP in water samples". Endocrine Disruptors 3.1 (2015): e981442.

5. Bergman A., et al. "The impact of endocrine disruption: A consensus statement on the state of the science". Environmental Health Perspectives 121 (2013): 104-106.

6. Chen LW., et al. "90d Exposure to nonylphenol has adverse effects on the spermatogenesis and sperm maturation of adult 
male rats". Biomedical and Environmental Sciences 27 (2014):

907-911.

7. Wu JJ., et al. "Differential effects of nonylphenol on testosterone secretion in rat Leydig cells". Toxicology 268.1-2 (2010): 1-7.

8. Bremer AA and Miller WL. "Regulation Of Steroidogenesis". Cellular Endocrinology in Health and Disease (2014): 207-227.

9. El-Dakdoky MH and Helal MA. "Reproductive toxicity of male mice after exposure to nonylphenol". Bulletin of Environmental Contamination and Toxicology 79.2 (2007): 188-191.

10. Lavoie HA and King S R. "Transcriptional regulation of steroidogenic genes: STARD1, CYP11A1 and HSD3B". Experimental Biology and Medicine234 (2009): 880-907.

11. Kusum K., et al. "Exposure of 4-Nonylphenol: Effect on Physiology and Reproductivity of Male Mice". Journal of Clinical and Diagnostic Research 15.3 (2021): AC01-AC05.

12. Kim YB., et al. "Adverse effect of nonylphenol on the reproductive system in $\mathrm{f} 1$ male mice: A subchronic low-dose exposure model". Development and Reproduction 23.2 (2019): 93-99.

13. Yucedag F., et al. "The effects of Nonylphenol on hearing in rats". International Advanced Otology 10 (2015): 76-79.

Volume 4 Issue 7 July 2021 (C) All rights are reserved by Radha Chaube., et al. 